\title{
El alquiler de vientre y el delito*
}

\section{Commodification of the womb and crime}

\section{Ángela Viviana López Bermúdez ${ }^{* *}$ Martín López Loaiza ***}

*El presente artículo se deriva del proyecto“El Alquiler de Vientre y el Delito”, Facultad de Derecho Corporación Universitaria Empresarial Alexander Von Humboltd, Armenia - Quindío. Colombia.

** Abodaga, especialista en derecho probatorio penal. Docente investigadora en la Universitaria Empresarial Alexander Von Humboltd integrante del grupo de investigación Filius.

***Joven Investigador adscrito al Programa de Derecho, Grupo de Investigación Filius. Corporación Universitaria Empresarial Alexander Von Humboldt. Armenia - Colombia.

Cómo citar: López, A.V., López, M. (2018) El alquiler del vientre y el delito. Inciso, 20(2); 1-13.

Recibido:29/02/2018 Revisado: 03/05/2018Ａceptado: 10/12/2018

DOI: http://dx.doi.org/10.18634/incj.20v.2i.892

\section{Resumen}

La investigación respondió, en el contexto del ordenamiento jurídico colombiano, al interrogante de si es viable considerar el alquiler de vientre como una conducta penalmente reprochable, para lo cual se desarrollaron cuatro objetivos:1) Describir el contexto histórico y conceptual del alquiler de vientre;2) Establecer la regulación existente en Colombia con respecto al alquiler de vientre; 3) Analizar el manejo jurídico y jurisprudencial del alquiler de vientre en otros países que han regulado el tema; y 4) Determinar los elementos integrantes del tipo penal del alquiler de vientre a introducir en la legislación colombiana. Se utilizó un enfoque epistemológico histórico hermenéutico, abordado desde un modelo cualitativo, de alcance exploratorio y descriptivo, para lo cual se aplicó el método de análisis documental en tres etapas: exploratoria, análisis de la información, y de interpretación. En la fase exploratoria se recurrió a fuentes de información primaria: legislación, doctrina, jurisprudencia y leyes en el contexto colombiano. En la fase de análisis de la información se usaron diferentes instrumentos de análisis como fichas de análisis documental, fichas RAE, mapas conceptuales, matrices de análisis. La fase de interpretación requirió la articulación de la información analizada, y las conclusiones se elaboraron a partir de la revisión crítica y problematizadora en relación con su contexto legal, social e histórico. La investigación obtuvo como resultado la creación de un instrumento que podría ser utilizado por el Congreso de la República para establecer una regulación del alquiler de vientre, de cara a la realidad social colombiana.

Palabras clave: Alquiler de Vientre, Contrato, Tipicidad, Antijuricidad, Ilícito
This investigation responded, in the context of the Colombian legal system, to the question of whether it is viable to consider commodification of the womb (womb rental) as a criminally reprehensible behavior, for which four objectives were developed: 1) To describe the historical and conceptual context of commodification of the womb; 2) To establish the existing (legal) regulation in Colombia regarding commodification of the womb; 3) To analyze the legal and jurisprudential management of commodification of the womb in other countries that have regulated that issue; and 4) To determine the legal (penal) constituent elements of commodification of the womb to be introduced in Colombian legislation. We used a hermeneutical, historical, epistemological treatment, which was approached from a qualitative model, of exploratory and descriptive scope, for which the method of documentary analysis was applied in three stages: exploratory, analysis of information, and interpretation. In the exploratory phase, sources of primary information were used: legislation, doctrine, jurisprudence and laws in the Colombian context. In the information analysis phase, different analysis tools were used, such as Document Analysis Worksheets, RAE files, conceptual maps and analysis matrices. The interpretation phase required the articulation of the information analyzed; the conclusions were drawn from critical and problematizing review, in relation to its legal, social and historical context. The research resulted in the creation of an instrument that could be used by the Congress of the Republic to establish a regulation of commodification of the womb, facing the Colombian social reality.

Keywords: Commodification of the womb, contract, typicality, unlawful, illicit

\section{INCIST}




\section{Introducción}

Desde que la ciencia descubrió la fertilidad in-vitro y el genoma humano, la forma de concebir a los seres humanos ha sobrepasado los límites del derecho, encontrándose con nuevas formas de generar vida humana, la alteración de fenotipos e incluso la clonación de seres vivos. No obstante, la ciencia médica siempre está varios pasos delante de la legislación, razón por la cual existen vacíos normativos que permiten que los integrantes de la sociedad llevados por el ánimo de lucro, se aprovechen de tal situación y tal es el caso del alquiler de vientre, una práctica que no se encuentra regulada en nuestra legislación colombiana, pero que cada día toma más auge para la creación de vida y como negocio económico.

Es por ello, que este proyecto de investigación propende por determinar la práctica de esta conducta no como un ejercicio lícito o comercial, sino como una práctica ilegal al existir una promesa remuneratoria y cuyo objeto es un ser humano, siendo de relevancia jurídica y social el estudio de este fenómeno a la luz de la política criminal estatal.

Paratalfin, estudiamoscasuísticayjurídicamente la legislación colombiana, así mismo hicimos uso del Derecho comparado para profundizar sobre la viabilidad de tipificar dicha conducta de cara a la realidad económica y social del país. Esto sin desconocer el dinamismo de las relaciones jurídicas y de la ciencia con el fin de acrecentarlas, pero regulándolas en razón de que no se vulneren bienes jurídicamente tutelados como la dignidad, la libertad, la vida e integridad personal del que está por nacer a cambio de una promesa remuneratoria.

Es necesario entonces partir del artículo primero de nuestra Constitución Nacional en el que establece que Colombia es un Estado social de derecho fundado en el respeto de la dignidad humana. Para Dworking (1978), la dignidad es esencialmente el libre ejercicio de la autonomía.
En cambio, Finnis (2011) cree que la dignidad está más profundamente ubicada, es la capacidad radical de ejercer la autonomía, que se sitúa en la raíz misma de la naturaleza humana. Esta capacidad radical, de elegir, de amar, de ejercitar la propia autonomía, está presente únicamente en la persona humana desde la concepción, y es lo que lo distingue de otros seres vivos.

En sentencia de la Corte Constitucional existe una exposición que resulta interesante traer a colación y que corresponde a la Posición de la Procuraduría General de la Nación respecto a la Dignidad Humana, veamos:

“...el derecho a la vida, sin la observancia del principio de la dignidad humana, perdería toda su potencialidad como valor jurídico esencial y, por ende, insoslayable, dentro de un orden normativo que considera al hombre como fin en sí mismo y no como un medio para que otros realicen mediante él objetivos que le son ajenos.

Cuando la vida del ser humano no está garantizada y regulada bajo la égida del principio de la dignidad humana, el hombre y la mujer quedan expuestos a la instrumentalización de sus existencias y, como consecuencia de ello, a ser reducidos a la degradante condición de una cosa, de la cual se sirven o sobre la cual deciden los demás..."(C-355, 2006).

Al respecto, la Corte Constitucional en su vasta jurisprudencia ha desarrollado dicho concepto; sin embargo, la sentencia T-881 de 2012, reunió todo ese análisis jurisprudencial, concluyendo que la dignidad humana caracteriza de manera definitoria al Estado colombiano como conjunto de instituciones jurídicas. La importancia práctica de esta "faceta" de la dignidad humana está mediada simplemente por la posibilidad de claridad conceptual.

En este sentido, se parte en la presente investigación desde el principio de la Dignidad Humana, por cuanto con el alquiler de vientre 
se está convirtiendo al nasciturus en un objeto contractual, dentro del cual se pacta un precio para su concepción. Este hecho conlleva a una presunta vulneración a la dignidad al ser tratado, este menor, como un objeto o cosa y, si bien las nuevas tecnologías y las ciencias han permitido la evolución del ser humano, ello no debe ser óbice para soslayar la dignidad humana y suscribir contratos ilegales con fines lucrativos que van en contra de la integridad del ser humano.

\section{Regulación del alquiler de vientre en Colombia}

En Colombia, el alquiler de vientre si bien no está expresamente prohibido tampoco se ha proferido una ley destinada a regular específicamente la materia, puesto que el tema de alquiler de vientre tiene más desarrollo jurisprudencial que normativo.

Fue con el Decreto 1546 de 1998 expedido por la Presidencia de la República de Colombia (1998), modificado parcialmente por el Decreto 2493 de 2004, reglamentario de las Leyes 9 de 1979 y 73 de 1988 que reglamenta la "obtención, donación, preservación, almacenamiento, transporte, destino y disposición final de componentes anatómicos y los procedimientos para trasplante de los mismos en seres humanos, y se adoptan las condiciones mínimas para el funcionamiento de las Unidades de Biomedicina Reproductiva, Centros o similares", que permite sentar la idea que en nuestro ordenamiento jurídico colombiano el procedimiento de reproducción humana asistida sí es autorizado, materializando así el principio de autonomía que profesa la Constitución Política para con los colombianos y más aún el derecho que les asiste a las personas a formar una familia.

Al respecto, la Sentencia T- 968 de 2009 de la Corte Constitucional-Sala Segunda de Revisión con Magistrada Ponente María Victoria Calle Correa, fue de gran importancia como precedente jurisprudencial para el tema del alquiler de vientre porque en ella la Corte aborda como problema jurídico:

“¿Están legitimados los convenios o acuerdos respecto de las técnicas de reproducción asistida, dentro de las cuales se ubica la maternidad subrogada o sustituta, en virtud del artículo 42-6 constitucional, el cual prevé que $\triangleleft$ Los hijos habidos en el matrimonio o fuera de él, adoptados o procreados naturalmente o con asistencia científica, tienen iguales derechos y deberes $\gg$ ? (Corte Constitucional. 2009).

La sentencia mencionada, en sus consideraciones resalta, que la reproducción asistida requiere del material genético de ambos padres del niño, donde la única labor de la madre sustituta se limita agestar el embrión. Para la Corte, este punto no encuentra prohibición alguna frente a este tipo de procedimientos, debido a que están regulados en el Decreto 2493 de 2004. En ese orden de ideas, la controversia se genera en el momento en que la mujer que alquila su vientre aporta su material genético, se estaría comprometiendo a entregar a su hijo biológico a cambio de una suma de dinero, comportamiento que prohíbe nuestro ordenamiento jurídico y que bien podría relacionarse con el delito de tráfico de personas. Bajo esta situación se desdibuja el fin principal que persigue el uso de estos métodos de reproducción, al momento de presentarse una intención de lucro; por tal motivo la Corte Constitucional considera que no existe la figura de alquiler de vientre cuando la madre sustituta aporta material genético.

Finalmente, en la mencionada sentencia la Corte dentro de sus competencias exhorta a la necesidad de legislar sobre este tema y establece unos requisitos que deberían ser tomados en cuenta para investir de validez este nuevo y ya tan popular método de reproducción indicando que: 
"...se ha evidenciado la necesidad de una "regulación exhaustiva y del cumplimiento de una serie de requisitos y condiciones" como los siguientes: (i) que la mujer tenga problemas fisiológicos para concebir; (ii) que los gametos que se requieren para la concepción no sean aportados por la mujer gestante (quien facilita su vientre); (iii) que la mujer gestante no tenga como móvil un fin lucrativo, sino el de ayudar a otras personas; (iv) que la mujer gestante cumpla una serie de requisitos como mayoría de edad, salud psicofísica, haber tenido hijos, etc.; (v) que la mujer gestante tenga la obligación de someterse a los exámenes pertinentes antes, durante y después del embarazo, así como a valoraciones psicológicas; (vi) que se preserve la identidad de las partes; (vii) que la mujer gestante, una vez firmado el consentimiento informado, e implantado el material reproductor o gametos, no pueda retractarse de la entrega del menor; (viii) que los padres biológicos no pueden rechazar al hijo bajo ninguna circunstancia; (ix) que la muerte de los padres biológicos antes del nacimiento no deje desprotegido al menor; y (x) que la mujer gestante sólo podría interrumpir el embarazo por prescripción médica, entre otros" (Sentencia T- 968 de 2009).

\section{¿Qué paso luego que la corte constitucional ordenó regular el tema?}

Expertos citan que el ánimo de lucro es el ítem que genera más problemática en la práctica del procedimiento de maternidad subrogada, ya que pocas personas realizarían tal proeza, sin esperar nada a cambio, debido a las múltiples consecuencias que la maternidad trae consigo. En concreto, Palomino (2014), haciendo referencia a Emilssen González de Cancino, directora del Centro de estudios sobre genética $y$ derecho de la Universidad Externado, señala que, "en general, en los sistemas de derecho civil que hablan de trasplantes y de disposición del cuerpo, se prefiere la gratuidad. Sin embargo, aunque en Colombia se cobra por esto, es difícil que se considere un delito porque nada lo señala así".

Sin embargo, Palomino (2014), retomando a Paulo Ernesto Realpe, coordinador de control constitucional y estrategias jurídicas del ICBF, advierte que en estos casos "debe tenerse en cuenta que el Decreto 2493 de 2004 establece en el artículo 15 la prohibición de remuneración o cualquier tipo de compensación o retribución por la donación o suministro de un órgano o tejido, concepto dentro del cual se entienden incluidas todas las partes vivas que constituyen el organismo humano".

Adicionalmente, es necesario abordar el tema de los derechos del recién nacido; dado que este posee como derechos fundamentales $y$ prioritarios a conocer a sus progenitores, a tener una vida digna, a tener una familia, a ser reconocido por sus padres, lo que hace que el tema se llene de delicadeza y obligue al Estado a regularlo con urgencia. Lastimosamente, a casi 6 años de la providencia de la Corte Constitucional, el Congreso aún no se ha pronunciado sobre el tema, lo que está causando problemas en la filiación de los bebés concebidos por medio de esta práctica, como lo sugiere Palomino (2014), citando a González de Cancino: "En Colombia no están claras las reglas de cómo se tiene un hijo a través de otra mujer. Por lo que aplica la normativa que existe para partos naturales; es decir que, ante el notario, el bebé deberá ser registrado con los apellidos de la mujer que alquiló su vientre y de su esposo o compañero permanente, si lo tiene".

Ello quiere decir, que procedimentalmente para adquirir la patria potestad del menor se debe presentar ante un juez un proceso de impugnación de paternidad, para que, con la prueba de genética, se demuestre que es suyo, o en el caso de que la madre de alquiler no tenga esposo o compañero sentimental, la pareja del contratante queda como padre del bebé y es posible adelantar un proceso legal de adopción. Cualquiera de los 
dos caminos requiere un tedioso proceso, por el cual tienen que pasar las personas que recurren al alquiler de vientre, lo que resulta en un dilema difícil de resolver, debido a que no se puede, vigilar, no está reglamentado y tampoco se puede penalizar.

Los galenos expertos en la materia han renunciado en su mayoría a practicar el alquiler de vientre en sus clínicas debido al gran vacío que les impide tener la seguridad de que el bebé será entregado a la hora del nacimiento, o simplemente que les impide saber si él bebe será bien recibido independientemente de las condiciones en que este nazca.

Por otra parte, Ricardo Luque, director de promoción y prevención del Ministerio de Salud, reconoce que se han visto con las "manos atadas" para vigilar el tema al no existir normas que lo regulen, por lo que su papel se ha limitado a ser garante de los servicios de reproducción asistida, que se basa en los estándares que señaló la resolución 2003 de 2014, en la que se definen los procedimientos y condiciones de inscripción de los prestadores de servicios de salud (El tiempo, 2014).

¿Qué artículos de la Constitución Nacional nos permite determinar si el alquiler de vientre es legal o ilegal?

\section{Fundamentos para su legalidad.}

“ARTÍCULO 42- “(..._L_Los hijos habidos en el matrimonio ofuera de él, adoptados o procreados naturalmente o con asistencia científica, tienen iguales derechos y deberes. La ley reglamentará la progenitura responsable.(...)" (Cursiva y subrayado fuera de texto original) (Asamblea Nacional Constituyente. 1991)

\section{Fundamentos para su ilegalidad.}

"ARTÍCULO 1- Colombia es un Estado social de derecho, organizado en forma de República unitaria, descentralizada, con autonomía de sus entidades territoriales, democrática, participativa y pluralista, fundada en el respeto de la dignidad humana, en el trabajo y la solidaridad de las personas que la integran y en la prevalencia del interés general.

ARTICULO 17- Se prohíben la esclavitud, la servidumbre y la trata de seres humanos en todas sus formas". (Asamblea Nacional Constituyente. 1991)

\section{Desarrollo conceptual del artículo 134 del Código Penal Colombiano.}

Como es sabido, en Colombia hay un gran vacío legal, en la materia de alquiler de vientres o maternidad subrogada, hasta el momento las altas cortes, particularmente la Corte Constitucional, ha sido la única que se ha pronunciado acerca del tema, en la sentencia T-968 de 2009 (pronunciamiento respecto a un caso concreto), con lo cual se hace difícil utilizar la misma para solventar casos futuros que tal vez tengan particularidades ajenas a las mencionadas por la Corte; así pues los procedimientos que llevan al llamado contrato de alquiler de vientre flotan en un limbo que, a la fecha se espera que el Congreso regule, para que se tenga total garantías en cuanto a los derechos de las partes contratantes, como también los del bebe que está por nacer.

En nuestro código penal vigente solo habría un artículo que se refiere a la materia, lo encontramos en el titulo 1 del libro $2^{\circ}$, capitulo octavo llamado delitos contra la vida y la integridad personal, artículo 134, el cual versa lo siguiente:

"Fecundación y tráfico de embriones humanos: el que fecunde óvulos humanos con finalidad diferente a la procreación humana, sin perjuicio de la investigación científica, tratamiento o diagnostico que tengan una finalidad terapéutica con respecto al ser humano objeto de la investigación incurrirá en prisión de 1 a 3 años. En la 
misma pena incurrirá el que trafique con gametos, cigotos o embriones humanos, obtenidos de cualquier manera o a cualquier título". (Código Penal Colombiano, 2000)

En este capítulo el legislador, solventa la protección contra los delitos que incurren contra la vida y la integridad personal, incluyendo así la clonación o repetividad del ser humano, la manipulación genética, y el que nos compete la fecundación y el tráfico de embriones, en el caso particular de nuestro artículo, el legislador no califica el sujeto activo que podría realizar la conducta o incurrir en el tipo penal, debido a lo difícil que sería cualificar el mismo, por la diversidad de títulos que expiden las universidades en materia de especializaciones, ya que por lo general estas prácticas que incluye el tipo penal suelen ser practicadas por equipos de especialistas en las distintas áreas de las ciencias biológicas: médicos clínicos, biólogos moleculares, genetistas, etc., sería interesante estudiar la situación jurídica de quien las realiza sin estar legamente autorizado, la responsabilidad de los integrantes del equipo profesional y la posible comisión del delito de concierto para delinquir.

Además del vacío en la norma acerca del tema que nos compete, también es bien sabido por análisis exhaustivos de grandes juristas del derecho colombiano que el legislador cometió un error científico al redactar este artículo, como se menciona en el libro lecciones de derecho penal, de la universidad el externado, en el capítulo de manipulación genética:

...en su rúbrica hablan de fecundación de embriones y estos son precisamente el resultado de la fecundación de los óvulos y no necesitan fecundación posterior para desarrollarse; igualmente que no respetaron el principio de proporcionalidad de las penas por cuanto señalaron la misma para quien trafique con gametos que para quien lo haga con cigotos y embriones, si bien es claro que los gametos-óvulos y espermatozoides- no merecen la misma consideración jurídica que las restantes entidades citadas en la norma... (Universidad Externado de Colombia. 2014).

También podemos apreciar que, los redactores, en este artículo dejan por fuera o no hacen mella en los tratamientos terapéuticos y la investigación de esta índole que se puedan dar en pro de la salud o a aliviar el sufrimiento de las personas, lo que el derecho a tratado de depurar y de tener los suficientes controles sobre este tipo de materias, debido a los avances científicos, orientados a la mejor vida de la humanidad. Resulta pertinente preguntarnos ¿Debe entenderse que se incurre en el delito cuando se insemina artificialmente a una mujer que hace las veces de madre portadora o se le transfiere a ella un embrión creado in vitro? la penalización de los contratos de gestación sustitutiva, nos ha merecido siempre un rechazo rotundo porque determina, sin fundamento suficiente, que una persona nazca con el estigma de hacerlo en el marco de un delito.

La maternidad subrogada, es vista por la sociedad colombiana, como un tema tabú, ya que es un modelo relativamente nuevo en nuestro país, debido a muchas circunstancias, una de ellas es el evidente vacío legal que hay acerca de la materia, y que el órgano legislativo y los órganos de cierre de las jurisdicciones, han preferido no tocar, sin tener en cuenta que es utilizada por cierto cumulo de parejas las cuales están imposibilitadas para tener hijos propios, ya sea por problemas físicos o de cualquier otra índole. Adicional a esta situación, se encuentra la interpretación espiritual o religiosa, principalmente por la fe católica, que la califica en primera medida denigrante para la mujer que se presta para tal uso, tanto también para los padres biológicos que ponen su material genético en otro cuerpo lo cual va en contra de todas las leyes biológicas que estos establecen. Resulta atroz la figura que se presenta luego de la entrega de un hijo a unos padres distintos a los 
que naturalmente lo concibieron, considerándose indigno, aun cuando se evidencia que algunas otras corrientes religiosas lo permiten, como lo es en la religión judía ortodoxa en la cual está permitido, debido a un texto encontrado en el génesis capítulo 30 versículo 1, en el cual relatan la historia de cómo Raquel no podía tener hijos y le pide a su concubina que tuviera los hijos de Jacob, entre muchos otros relatos.

Está latente la posibilidad que en la maternidad subrogada, se hallen modelos de alguna clase de conducta antijurídica, debido a que si bien es claro que el material genético utilizado para la fecundación pertenecen a la pareja que busca alquilar el vientre, pero a la hora en la que nazca él bebe, este será registrado con una madre y un padre diferentes, lo que significa que el médico que asista el parto desde el momento en que formule el certificado de nacido vivo incurriría en falsedad en documento público, y la madre natural al momento de entregar a el recién nacido a los padres genéticamente naturales, podría estar cometiendo trata de personas con el neo nato, en razón del factor económico a cambio de su participación en el proceso. Sin embargo cabe la posibilidad que la madre subrogada al momento de dar a luz se rehúse, a hacer la entrega de su hijo debido a todos los lasos afectivos que esta forma con el mismo durante la gestación, así pues ¿Quién reconocería a los padres que hicieron el alquiler, las sumas que estos invirtieron en la manutención de la madre subrogada?; se evidencia el latente peligro del vacío legal, tendiente a vulnerar la seguridad jurídica de más de las partes que incurren en esta práctica actualmente.

Es alarmante, que ante la inseguridad jurídica, se ha empezado a incursionar en tal práctica de manera clandestina, tornándose en un salvavidas temporal ante la difícil situación económica que por lo general es el motor que impulsa a muchas mujeres a tomar la decisión de hacer parte de este "negocio".
Cierto es que la práctica de la maternidad subrogada, es la solución a muchos de los problemas actuales para las parejas que por motivos ajenos a ellas no pueden concebir por sus propios medios, y que no optan por la adopción de un bebe, pero cuando esta involucra estos tediosos y complicados trámites legales, que de por si no fueron creados para la medida, se torna en una práctica oscura, que tarde o temprano causara graves consecuencias; es una necesidad absoluta la que al día de hoy se presenta de que las grandes cortes y el órgano legislador, se pronuncie en la materia y regulen con requerimientos, lineamientos y reglas básicas a partir de las cuales haya seguridad tanto para las partes como para él bebe, de que la práctica se dé en el ámbito de las buenas costumbres y la legalidad.

\section{Manejo jurídico y jurisprudencial del Alquiler de Vientres o Maternidad Subrogada en otros países que han regulado el tema.}

A nivel internacional, en los diferentes países que han regulado el tema se vislumbran tres posiciones frente al alquiler de vientre: (1) admisión amplia, aun con fines comerciales., (2) admisión de esta práctica solo bajo criterios altruistas, y con el cumplimiento de ciertos requisitos y condiciones, (3) prohibición de la gestación por sustitución, siendo menester analizar cada una de estas regulaciones de la siguiente manera:

Ucrania es uno de los países en los que se permite la gestación subrogada de manera amplia, es decir, bien sea se forma comercial o de forma altruista; es además, uno de los centros mundiales más acreditados de maternidad subrogada.

En este sentido, el artículo 123 del código familiar de ese país, regula la determinación del origen del niño nacido en resultado de aplicación de técnicas de reproducción asistida y, en el mismo artículo se establece que: 
1. mujer dé luz al niño concebido en virtud de aplicar las técnicas de reproducción asistida, realizadas en base del acuerdo por escrito de su marido, él se inscribe como el padre de niño. (Nota: el artículo se aplica también en los casos de maternidad subrogada tradicional)

2. Una vez que en el cuerpo de otra mujer se transfieran el embrión humano concebido por los esposos (hombre y mujer) en virtud de aplicar las técnicas de reproducción asistida, los padres del niño son los esposos. (Nota: el artículo se aplica en los casos de maternidad subrogada por gestación) (Sáenz, 2016)

De otro lado, el anexo de la ley de Ucrania sobre trasplante de órganos y otros materiales anatómicos humanos del 16 de julio de 1999, establece que la pareja que haya dado su consentimiento para la aplicación de técnicas de reproducción asistida ejercerá en su plenitud la patria potestad con respecto al niño nacido mediante dichas técnicas. (Parrilla, 2008)

Al igual que Ucrania, Rusia reconoce la validez de la gestación subrogada y se encuentra regulado por diferentes normas que hacen parte del ordenamiento jurídico del país. Es el caso de los artículos 51,4 y 52,3 del Código de Familia, el artículo 35 de la ley sobre la protección de la salud de los ciudadanos de la Federación Rusa, así como el artículo 16,5 de la ley federal sobre las actas de estado civil. De acuerdo con la legislación Rusa, no importa la nacionalidad de las personas que deseen acogerse al alquiler de vientres, así como tampoco el estado civil de las personas, deben existir ciertas indicaciones médicas para recurrir al servicio de alquiler de vientre, igual sucede con la nacionalidad de los usuarios. Cuando el niño haya nacido, la madre gestante debe dar su autorización para que los padres intencionales sean los inscritos en el registro civil como padres del niño, siendo así que a partir de este momento la madre gestante perderá sus derechos como madre sobre el recién nacido. (Scotti, 2013)
Otro de los países en los que se permite la utilización de métodos de reproducción asistida de forma amplia es Estados Unidos. En este punto, hay que recordar que esté es un país federado, de acuerdo con esto, la legislación entre uno y otro estado puede variar; lo anterior ha generado que, no exista una postura uniforme respecto de la validez jurídica del tema.

Ahora bien, haciendo referencia a los estados en los que se reconoce validez a esta clase de contrato, tenemos que, a partir de 1993, cuando se dictó sentencia dentro del caso Johnson Vs. Calvert en California, se consideran como padre del bebé quienes aportan el material genético. En el fallo, la Corte indicó que para efectos de la fijación de la filiación se necesitaba estar en el momento de la concepción, lo que permitía deducir que en ese momento, la madre biológica era la única que tenía la intención de ser madre, razón por la cual, era está quien debía ser reconocida como madre legal. (Molina, 2014). En el estado de Ilinois es requisito que la gestante tenga como mínimo 21 años de edad, que haya tenido un hijo antes, igualmente debe pasar por un reconocimiento médico. Es necesario suministrar información tanto a los padres comitentes como a la gestante respecto del alcance jurídico del contrato, así mismo, la legislación en este estado ordena que, la gestante debe entregar el hijo a los comitentes justamente después de su nacimiento y estos deben aceptar la guarda del niño. En lo que respecta al estado de Virginia, poder realizar un contrato de gestación subrogada, requiere una autorización previa por parte del tribunal. Si se aprueba el contrato, los padres intencionales serán los padres legales; si por el contrario, el contrato es declarado nulo, la madre subrogada y su marido en caso de haberlo serán declarados padres legales, lo que genera como consecuencia que los padres intencionales solo puedan adquirir los derechos como padres por medio de la adopción; a pesar que el tribunal haya aprobado el contrato, si la gestante es la madre genética, podrá rescindir el contrato dentro de los primero seis meses de embarazo. 
Admisión de esta práctica solo bajo criterios altruistas, y con el cumplimiento de ciertos requisitos y condiciones.

En la actualidad existen países cuya legislación permiten la utilización de un vientre alquilado siempre y cuando tenga fines altruistas y con el cumplimiento de ciertos requisitos y condiciones, siendo así, que se prohíbe rotundamente algún tipo de contraprestación económica por el alquiler del vientre; bajo este grupo se encuentran, Reino Unido, Canadá, Brasil, Israel, Grecia, México DF, Australia, Sudáfrica y Nueva Zelanda; estos países se pueden clasificar, de 2 maneras:

- Los países que permiten el alquiler de vientre, pero primero se debe hacer una pre-aprobación, en donde los comitentes y los gestante deben presentar el acuerdo al que pretenden llegar a una autoridad competente, la cual es la encargada de mirar si es viable aquel, y así determinar si lo aprueban o no, determinando si cumplen los lineamientos plasmados por el ordenamiento frente al tema.

- Por otro lado encontramos los países donde su regulación se refiere a poner en marcha un procedimiento para que los comitentes obtengan la paternidad legal del niño nacido como resultado de un acuerdo de gestación por sustitución ex post facto. Aquí la atención se centra en la transferencia de la filiación post-parto.

Como se puede ver el primer grupo se centra en mirar la viabilidad, factibilidad del acuerdo entre los comitentes y los gestantes, se podría entonces decir que una vez aprobado aquel acuerdo por la autoridad competente, se vuelve una obligación para los gestantes posterior al parto entregarles el nacido a los comitentes, debido a que ellos en el acuerdo figuran como padres; por el contrario en el segundo grupo la filiación se tramita después de nacido él bebe, dándose la posibilidad de que los gestantes no quieran entregar el niño, suscitándose un gran controversia, pues se tendría que determinar quiénes deben ser los padres, hacer un examen exhaustivo y poner en una balanza ambas partes; situación compleja tanto para los comitentes como para los gestantes, que querrán tener al recién nacido bajo su custodia.

Ejemplo de ambos grupos se evidencia en Israel, la Ley 5746 sobre acuerdos de gestación por sustitución de 1996, (Scotti,2013) la ley exige que los comitentes deben ser una pareja conformada por una mujer y un hombre, acreditar su infertilidad o incapacidad de llevar a cabo el proceso de gestación, los embriones deben haberse creado "in vitro" con los genes de los comitentes; no debe existir relación entre la gestante y la comitente, la gestante debe ser soltera, de lo contrario el Comité evaluara el caso concreto, la gestante debe profesar la misma religión de la comitente, el acuerdo debe ser aprobado por un comité. Igualmente se establece que la paternidad legal de un niño nacido por gestación por sustitución tiene que ser autorizada por orden judicial; sin embargo, la regla por defecto establecida por dicha ley establece que los comitentes deberán ser los padres legales del niño, en caso de solicitud de rescindir el contrato, el Tribunal analizara si han cambiado las circunstancias que justifiquen tal acción, buscando el bienestar del recién nacido; además tras la concesión de una orden de paternidad, la gestante no podrá rescindir el contrato.

Así mismo en Grecia la gestación por sustitución está regulada por dos leyes: la ley 3089/2002 y la ley 3305/2005; siendo así que los contratos de subrogación deben cumplir con unos requisitos, legalmente establecidos en Grecia,; Así, el artículo 1458 de la ley 3089/2002 establece que la transferencia de un óvulo fertilizado a otra mujer y su embarazo deberá ser permitida por autorización judicial expedida antes de la transferencia, la cual será dada previo acuerdo escrito y sin beneficios económicos entre las partes implicadas, acreditando que la mujer es medicamente incapaz de concebir un hijo. (Haztis. 2009) 


\section{Prohibición de la gestación por sustitución}

En contravía a los países que reconocen la validez jurídica de la maternidad subrogada, existen otros donde esta práctica está prohibida, como el caso de Francia, Alemania, Suecia, Suiza, Italia, Austria, Australia, Noruega, España, en estos países el alquiler de vientres es por regla general prohibido, las siguientes manifestaciones exponen algunos de los argumentos:

- "El Comité de Francia en su opinión núm. 3 del 23 de octubre de 1984, afirma estar en contra de esta práctica, ya que ella puede llevar a fines comerciales, y a la vulneración de derechos de la madre gestante por la explotación mental y material que puede tener.

- Alemania por medio de la ley de protección del embrión 745/90 del 13 de diciembre de 1990, en su art. 1, referido a la utilización abusiva de las técnicas de reproducción, establece que: "1. Será sancionado con una pena privativa de la libertad de hasta tres años o de una multa quien: 1) Procediera a transferir a una mujer el óvulo de otra; 2) Fecundara artificialmente un óvulo con fines distintos que los de iniciar un embarazo en la mujer de quien proviene el óvulo; [...]; 7) Fecundara artificialmente o transfiriera un embrión a una mujer dispuesta a entregar el niño a terceros luego de su nacimiento". (Consejo Nacional de Investigaciones Científicas y Técnicas. S.F.)

Después de ver las diferentes regulaciones normativas a nivel mundial, es importante profundizar en la jurisprudencia internacional, en razón a su alto contenido conceptual y constante actualización, tomando como referencia los siguientes casos:

- En Francia: en el 2011 este país se reiteró en que la maternidad subrogada era contraria al orden público francés y que por lo tanto la transcripción en los registros de estado civil de las actas de nacimiento inscriptas en el extranjero respecto de niños nacidos de una madre de alquiler debía ser negada; en el caso $\mathrm{n}^{\mathrm{o}}$ 10-19053 (Corte de Casación, 2011).

- Reino Unido: En el 2014 una madre engendro el hijo de su hijo gay siendo soltero, siendo éste el primer caso de maternidad subrogada en dicho país; sin embargo, el problema en el caso concreto es que el niño nacido es hijo de la abuela y a su vez hermano del hijo de aquella. La solución legal según las leyes de aquel país, era adelantar el proceso de adopción por parte del hijo de la señora, luego entonces, surgió otro problema debido a que de acuerdo con esta legislación no es posible adelantar el proceso de adopción por una persona soltera; el caso llego al Tribunal Superior de Justicia según el cual, el procedimiento fue legal y aun cuando no debería entregarse un niño a un solo padre, el bebé y el sujeto estaban vinculados legalmente como hermanos, lo que hacia esta situación diferente, ya que, por ser hermanos no se estaba violando ninguna ley si se aprobaba la adopción.

- España: después de 4 años de relación, una pareja conformada por una mujer divorciada de 2 hijos de su anterior relación, y un hombre soltero, decidió engendrar un bebe, debido a que la mujer había sufrido cáncer de mama y dejo su tratamiento contra esta enfermedad para darle paso a la inseminación artificial, este procedimiento resulto fallido, lo cual llevo a que la pareja contratara a una madre de alquiler en los EE.UU., producto de lo cual nació su hija. Posterior a su nacimiento se disuelve la relación existente, haciendo que el hombre inscribiera la filmación de la menor como hija únicamente de él, en el país en donde se llevó a cabo el procedimiento, y a su vez en el registro civil español, 2 años después la ex-pareja de este hombre decidió presentar una demanda solicitando un régimen de visitas a su favor, argumentando que ella era la madre de la menor, a lo cual el hombre se opuso argumentando que la menor estaba inscrita en el registro civil solo como hija de este y que el proyecto de tener una hija había sido solo de idea de él, por lo que 
permitirle visitas, implicaría una confusión de roles para la niña. Luego del trámite procesal, el juzgado de primera instancia español, decide otorgarle el régimen de visitas a esta mujer, debido a que se probó en el proceso que el proyecto de tener un hijo era entre ambos.

Elementos integrantes del tipo penal del alquiler de vientres a introducir en la legislación colombiana

Teniendo en cuenta el desarrollo de los objetivos anteriores y en especial el pronunciamiento de la Corte Constitucional en Sentencia T- 968 de 2009, se tiene que para el caso colombiano la práctica del alquiler de vientres si bien no tiene una regulación legal, si posee un lineamiento jurisprudencial que permite el alquiler de vientre solo bajo criterios altruistas, $\mathrm{y}$ con el cumplimiento de ciertos requisitos y condiciones. Sin embargo, la prohibición por tener un fin lucrativo, resulta ineficaz, toda vez que al no existir una sanción por el incumplimiento de la falta de ánimo de lucro, es pasada por alto, considerándose permitida. Es por lo anterior que resulta viable la tipificación del alquiler de vientres o maternidad subrogada como una conducta penalmente reprochable, cuando se persigan fines lucrativos.

Cabe aclarar que desde un punto de vista netamente personal, se considera que dicha práctica hace parte del desarrollo científico de la humanidad y no se debe prohibir en su totalidad, pero teniendo en cuenta el estado económico en el que vive la mayor parte de la sociedad y la vulnerabilidad de nuestros ciudadanos ante los inescrupuloso de delincuentes y grupos delictivos dedicados a la explotación del ser humano, se torna necesario prohibir esta práctica en los eventos que exista animo lucrativo o fines de explotación y que la misma prevea una sanción de índole penal ante su violación.

Para tal fin se propone la configuración del siguiente tipo penal:

\section{Maternidad Subrogada, Alquiler de vientre o Gestación Subrogada.}

El que mediando compensación económica, fin lucrativo, provecho o cualquier utilidad, realice, organice o publique la maternidad por sustitución en cualquier forma incurrirá en prisión de uno a cinco años.

Con la misma pena serán castigados la persona que lo reciba, el intermediario y la mujer que alquile su vientre, aunque la práctica se hubiese efectuado en país extranjero.

- Clasificación: Mera Conducta, Básico, Completo, En Blanco, Principal o Incondicionado.

Elementos Normativos: Compensación económica, fin lucrativo, provecho, utilidad, hijo, descendiente, menor, filiación.

- Tipo Objetivo: Sujeto Activo. Indeterminado. Sujeto Pasivo. Menor. Conducta. Verbo Rector: Entregar - Alquilar. Bien Jurídico: La Familia

Tipo Subjetivo: Modalidad Dogmática:
Doloso.

\section{Conclusiones y recomendaciones}

En Colombia la maternidad subrogada, es categorizada como un tabú, debido a ser un modelo relativamente nuevo en nuestro país, razón por la cual, se evidencia un vacío legal en la materia, responsabilidad que no ha sido asumida totalmente por el órgano legislativo y los órganos de cierre de las jurisdicciones, que han preferido no tocar, ya sea por falta de información acerca del tema o por la confidencialidad con que es manejado en el país, a pesar que es una práctica cada vez más común para las parejas imposibilitadas para tener hijos propios.

La posibilidad de que la maternidad subrogada traiga consigo una conducta antijurídica, ya sea falsedad en documento público al momento de 
registrar al recién nacido con una madre e padre distinto a la madre natural o la trata de personas con el neo nato, cuando la contraprestación por el recién nacido se presenta antes y después de su entrega; genera un escenario peligroso para los intervinientes en este procedimiento médico, quienes exigen una normatividad clara que les permita salir de la confusión e incertidumbre, y en muchos casos, de la clandestinidad, normatividad que delimite lo permitido y lo prohibido.

El hecho de que actualmente esta actividad no se encuentre prohibida, deja a la autonomía de la persona y su libre albedrio, tanto de la madre de alquiler que se presta para la práctica como de la pareja que alquila el vientre, someterse a estos procedimientos, actuando así bajo un presunto manto de legalidad que el vacío jurídico le otorga a la maternidad subrogada. La problemática no solo afecta a las partes, sino que ataca directamente la seguridad jurídica del recién nacido, tiene derecho de ser reconocido filialmente por sus padres biológicos, derecho a ser tratados dignamente, a que su vida no se ponga en peligro por razones culturales, políticas o religiosas, a no ser separado de sus padres, entre otros.

Ante la necesidad de protección normativa, y aclarando que la práctica de estos procedimientos científicos ha traído consigo grandes avances para la humanidad y su preservación, en el presente artículo se propone la prohibición de la maternidad subrogada con fines lucrativos, presentando la configuración del siguiente tipo penal:

\section{Maternidad subrogada, alquiler de vientre o gestación subrogada.}

El que mediando compensación económica, fin lucrativo, provecho o cualquier utilidad, realice, organice o publique la maternidad por sustitución en cualquier forma incurrirá en prisión de uno a cinco años.
Con la misma pena serán castigados la persona que lo reciba, el intermediario y la mujer que alquile su vientre, aunque la práctica se hubiese efectuado en país extranjero.

\section{Referencias bibliográficas}

Asamblea Nacional Constituyente. (1991). Constitución Política de Colombia.

BIBLIA, D. J. (1971). Biblia de Jerusalén. Alianza Editorial-Desclée de Brouwer. Madrid-Bilbao.

Congreso de la República de Colombia (2000). Código Penal Colombiano. Ley 599 de 2000

Consejo Nacional de Investigaciones Científicas y Técnicas. (S.F.). Gestación por sustitución. Argentina.

Corte de Casación, (2011) $1^{a}$ Cámara

Civil, 06 de abril 2011.

Corte Constitucional. (2006).

Sentencia C-355 de 2006.

Corte Constitucional. (2009). Sentencia T- 968 de 2009

Corte Constitucional. (2012). Sentencia T-881 de 2012

Dworkin, R. (1978). Los Derechos en Serio (Vol. 136). Harvard University Press

El Tiempo, (2014). El alquiler de vientres aún no tiene reglas claras en Colombia.

Finnis, J. (2011). Natural law and natural rights. Oxford University Press. 
Hatzis, A. N. (2009), "From soft to hard paternalism and back: the regulation of surrogate motherhood in Greece", Portuguese Economic Journal, Vol. 49º núm. 3, pp. 205-220.

Molina-Martínez, E. (2014). Maternidad subrogada en derecho internacional privado español.

Palomino. (2014). Alquiler de Vientres en Colombia. El Tiempo.

Parrilla,P.(Ed.).(2008). Manual sobredonacióny trasplante de órganos. Arán Ediciones.

Presidencia de la República de Colombia (1998). Decreto 1546 de 1998.

Sáenz, Á. R. (2016). Tratamento de barriga de aluguel em Direito Comparado. Tempus Actas de Saúde Coletiva, 9(2), 121-132.

Scotti,L.(2013).Elreconocimientoextraterritorial de la "maternidad subrogada": una realidad colmada de interrogantes sin respuestas jurídicas. Pensar en Derecho, 1, 267-289.

Universidad Externado de Colombia. (2014). Lesiones de Derecho Penal Parte Especial. Segunda Edición. 2014. 